\title{
Interjurisdictional Linkages and the Scope for Interventionist Legal Harmonization
}

\author{
Andrzej Baniak \\ Peter Grajzl \\ CESIFO WORKING PAPER No. 3085 \\ CAtegory 2: Public CHOICE \\ JUNE 2010 \\ An electronic version of the paper may be downloaded \\ - from the SSRN website: \\ - from the RePEc website: \\ - from the CESifo website: \\ www.SSRN.com \\ www.RePEc.org \\ www.CESifo-group.org/wp
}




\title{
Interjurisdictional Linkages and the Scope for Interventionist Legal Harmonization
}

\begin{abstract}
We study the desirability of interventionist harmonization of legal standards across multiple, mutually interdependent jurisdictions which strive to adapt law to their local conditions as well as to synchronize it with other jurisdictions. In a setting where jurisdictions are privately informed about their local conditions, we contrast the regime of decentralized standard-setting with two means of interventionist harmonization: through centralization and through allocation of lawmaking authority to a particular jurisdiction. Our analysis illuminates the importance of patterns of interjurisdictional linkages in delineating the scope for, and the appropriate means of, interventionist harmonization. We find that greater jurisdictional interdependence - the hallmark of globalization - per se does not justify interventionist harmonization unless increased interdependence results in notable asymmetries in the pattern of jurisdictional interdependence. We also show that, in the presence of cross-jurisdictional externalities, harmonization is, contrary to conventional predictions, not desirable when local preferences are homogeneous across jurisdictions.
\end{abstract}

JEL-Code: D02, D82, K40, P50.

Keywords: harmonization, centralization, delegation, cross-jurisdictional externalities, jurisdictional interdependence, globalization.

\author{
Andrzej Baniak \\ Department of Economics \\ Central European University \\ Nador u. 9 \\ Hungary-1051 Budapest \\ baniaka@ceu.hu
}

\author{
Peter Grajzl \\ Department of Economics \\ The Williams School of Commerce, \\ Economics, and Politics \\ Washington and Lee University \\ USA - Lexington, VA 24450 \\ grajzlp@wlu.edu
}

April 23, 2010

For helpful comments, suggestions, and discussion, we thank Atin Basu, Martin Davies, Tim Diette, Valentina Dimitrova-Grajzl, Antony Dnes, Robert Dolan, Joseph Guse, Peter Kondor, Alan Marco, Peter Murrell, Zvika Neeman, and seminar participants at the Central European University, University of Richmond, and Washington and Lee University. 


\section{Introduction}

The debate about the pros and cons of legal harmonization has in the last two decades been prominent across the globe: top-down harmonization of laws and regulations has either taken root, is in progress, or has been contemplated within the European Union, the United States, Latin America, Africa and Asia. ${ }^{1}$ Moreover, in light of the ever-increasing global economic interdependence, legal harmonization has also been considered on a global scale (see, e.g, Rodrik 2000, 2001; Reich 2004; IUC Independent Policy Report 2009). ${ }^{2}$

Yet in spite of the increasing interest in legal harmonization, formal normative analyses of the subject are scant. Only a handful of contributions have examined conditions under which interventionist harmonization, orchestrated by a supra-jurisdictional authority, is socially desirable (see, e.g., Garoupa and Ogus 2006, Monheim Helstroffer and Obidzinski 2010, Ulph 2000, Loeper 2009). Moreover, the existing analyses have, as we argue in Section 2, with the exception of Loeper (2009), all studied the scope for interventionist harmonization within a stylized two-jurisdiction framework.

In this paper, we fill the gap in the existing literature by studying the normative aspects of interventionist harmonization of legal standards and institutions in a framework of multiple, mutually interdependent jurisdictions. As we show (see Section 5), the two-jurisdiction analysis pursued in the literature thus far, while undoubtedly illuminating, does not come without loss of generality. In particular, it falls short of deducing the full scope for interventionist harmonization on a global scale, where the pattern of interdependence among multiple jurisdictions can take on

\footnotetext{
${ }^{1}$ The literature debating pros and cons of legal harmonization in the EU and the United States is so voluminous that we abstain from enumerating specific references; see, however, Marciano and Josselin (2002) and Esty and Geradin (2001) for two edited volumes of contributions on the topic, and Garoupa and Ogus (2006) for further references. See respectively Mancuso (2006), Garro (1992) and Malang (2007) for discussion about legal harmonization in Africa, Latin America, and Asia.

${ }^{2}$ See also the articles of the symposium Worldwide Harmonisation of Private Law and Regional Economic Integration in vol. 8 of the 2003 Uniform Law Review.
} 
many different hues. ${ }^{3}$ The particular questions we address in the multiple-jurisdiction framework are: Should legal standards and institutions be harmonized across jurisdictions at a global level, and if yes, under what conditions and how? How does the nature of global interdependence affect the attractiveness of interventionist harmonization from the aggregate welfare point of view? Does greater global interdependence make harmonization more desirable?

The starting point of our analysis is the general trade-off inherent in the adoption of uniform institutional solutions (see, e.g., Oates 1972; Van den Bergh 2000; Alesina, Angeloni and Schuknecht 2005). ${ }^{4}$ The benefits of interventionist harmonization derive from the resolution of coordination problems, which arise under a decentralized standard-setting regime and increase transaction costs of cross-jurisdictional commerce (see, e.g., Ribstein and Kobayashi 1996, Parisi 2007, Carbonara and Parisi 2007). The costs of harmonization arise because one-size-fits-all institutional solutions are applied to heterogeneous environments (see, e.g., Van den Bergh 2000, Gomez 2008, Ganuza and Gomez 2008). Exploring the above trade-off in a multi-jurisdiction setting allows us to illuminate the salient, yet thus far neglected, role of patterns of jurisdictional interdependence.

As a benchmark, we consider a world where jurisdictions set their respective legal standards in a decentralized manner. Under a regime of decentralized standard-setting, every jurisdiction pursues conflicting goals of adopting legal standards which, on one hand, fit its own local conditions, and, on the other hand, are synchronized with the legal standards of other jurisdictions deemed of particular economic importance. The jurisdictions are choosing their

\footnotetext{
${ }^{3}$ An analytical analogy for why examining a world with two jurisdictions does not come without loss of generality can be found in the consumer choice theory: when the consumption set is restricted to two goods only, the wellknown properties of the Hicksian (compensated) demand imply that the two goods must be substitutes and cannot be complements (see, e.g, Mas-Colell et al. 1995, Proposition 3.G.2).

${ }^{4}$ Recent contributions in the literature have explored arrangements where centralized solutions do not impose institutional uniformity (see, e.g., Alesina, Angeloni and Etro 2005; Besley and Coate 2003, Lockwood 2002). In the formal literature on top-down legal harmonization, Monheim Helstroffer and Obidzinski (2010) allow for flexible harmonization in exploring the welfare effects of minimum standards in asylum law.
} 
respective legal standards non-cooperatively and under incomplete information about the local conditions prevailing in other jurisdictions — an assumption which is empirically justifiable and in line with the literature on federalism and constitutional design (see, e.g., Harstad 2007: 874; Ulph 2000).

The relative importance that jurisdictions assign to matching their legal standards to their own local conditions versus synchronizing their legal standards with other jurisdictions depends on the extent of jurisdictional interdependence. In an autarkic world, the extent of jurisdictional interdependence is low: jurisdictions care primarily about adopting laws and institutions that match their own local conditions. Accordingly, to the extent that jurisdictions are heterogeneous in their local conditions, the regime of decentralized standard-setting results in an equilibrium characterized by institutional diversity. Intuitively, in this scenario, an interventionist harmonization of global legal standards seems unwarranted due to the large global losses arising from the adoption of one-size-fits-all legal standards in diverse local environments.

In a globalized world, in contrast, the extent of jurisdictional interdependence is, by definition, large. Individual jurisdictions are, rather than matching legal standards to own local conditions, concerned primarily about synchronizing their respective legal standards with the legal standards in the rest of the world. Harmonization of legal standards across jurisdictions would therefore seem desirable, yet, when jurisdictions are incompletely informed about the local conditions prevailing in the rest of the world, possibly difficult to attain under decentralized legal standard-setting. Does greater global interdependence therefore require interventionist harmonization, as conventional wisdom holds (see, e.g., Casella and Feinstein 2002: 437; Sgard 2004: 387)? And if interventionist harmonization is desirable, how should it be attained? 
As we show in the paper, the answer lies in examining not the overall extent, but rather the pattern of jurisdictional interdependence. We find that the scope for interventionist harmonization may exist only when the pattern of jurisdictional interdependence exhibits structural asymmetries — that is, when there exists one or more 'focal' jurisdictions that the rest of the world could produce large benefits in synchronizing its institutions with, or even when there exists a jurisdiction which is largely 'autonomous' from the rest of the world and which may, but need not be, 'focal'. In the absence of such notable structural asymmetries in the pattern of jurisdictional interdependence, we show that there is no scope for interventionist harmonization of global legal standards— the regime of decentralized standard-setting unambiguously yields the greatest (expected) global welfare, regardless of the overall extent of jurisdictional interdependence. An important corollary to this result is that an overall increase in the global jurisdictional interdependence per se, contrary to customary beliefs (Casella and Feinstein 2002: 437), does not necessarily provide a rationale for interventionist harmonization.

To see why the presence of notable structural asymmetries in the pattern of jurisdictional interdependence generates the scope for interventionist harmonization, consider a world where jurisdictions wish to synchronize their legal standards with the legal standards of one particular jurisdiction, which we call 'focal' jurisdiction. Suppose, in addition, that the focal jurisdiction is largely 'autonomous' (that is, self-sufficient) in that it puts a relatively greater emphasis on adopting legal standards that match its own local conditions than synchronizing them with the rest of the world. Under a regime of decentralized standard-setting, all jurisdictions are therefore trying to mimic legal standards adopted in the focal jurisdiction. Yet the focal jurisdiction ignores the spillover effect of choosing legal standards, which fit its own local conditions, on the rest of the world. Because other jurisdictions have only incomplete information about the focal 
jurisdiction's local conditions, the rest of the world is unable to synchronize its standards with the standards of the focal jurisdiction. Hence, the focal jurisdiction's failure to internalize the abovementioned externality results in substantial global welfare losses. As a result, despite sizeable aggregate welfare costs from the misfit of uniform institutional solutions in diverse local environments, some form of interventionist harmonization of global legal standards may be desirable.

If interventionist harmonization is desirable, there remains the question of how it should be accomplished. Should the content of the common legal standards be determined by a representative supra-jurisdictional body such as the World Trade Organization, the International Institute for the Unification of Private Law ("UNIDROIT"), or the United Nations Commission on International Trade Law ("UNCITRAL")? ${ }^{5}$ Or is it ever desirable that the drawing up of common legal standards is left to one particular jurisdiction, as in the case of the United Nations' Convention on Contracts for the International Sale of Goods, the drafting of which was supposedly dominated by the United States (Herings and Kanning 2008)?

We therefore investigate two methods of interventionist harmonization. Under harmonization through centralization, the authority to set a common global legal standard is allocated to a central supra-jurisdictional authority. The supra-jurisdictional authority then chooses the common global legal standard, maximizing the expected aggregate welfare, but without knowing the individual jurisdictions' local conditions. ${ }^{6}$ Under harmonization through delegation, the authority to set a common global legal standard is, in contrast, allocated to one

\footnotetext{
${ }^{5}$ See Reich (2004) for an insightful discussion and comparison of the functioning of the WTO, UNIDROIT and UNCITRAL as law-harmonizing organizations.

${ }^{6}$ In this paper, we assume that the central supra-jurisdictional authority is benevolent and abstract from the role of politics in determining the substantive content of the common legal standards. See Section 7 for further remarks.
} 
particular jurisdiction. ${ }^{7}$ Informed about its own local conditions, the jurisdiction with the lawmaking authority selects its most preferred legal standard, which is then adopted by the rest of the world.

As we show in the paper, which of the two methods of harmonization-through centralization or through delegation-is superior when again depends on the pattern of jurisdictional interdependence. When there exists a focal jurisdiction which is itself fairly dependent on the rest of the world, harmonizing global legal standards through delegation to the focal jurisdiction is likely going to be inferior to harmonization through centralization. Intuitively, when the focal jurisdiction is primarily concerned with synchronizing its laws with the rest of the world (rather than matching its laws to own local conditions), then under harmonization through delegation the focal jurisdiction's extra benefit from the perfect fit of law to its local conditions does not compensate for the rest of the world's aggregate losses from misfit. In contrast, if the pattern of jurisdictional interdependencies is such that a focal jurisdiction is, in addition, largely autonomous (and therefore uninterested in synchronizing its legal standards with the rest of the world), then the global welfare may be greatest when the common global legal standard is in fact chosen by the autonomous focal jurisdiction.

The rest of the paper is organized as follows. Section 2 discusses our approach in light of the existing literature. Sections 3 through 6 develop and analyze the model. The model clarifies how the pattern of jurisdictional interdependence determines the scope for interventionist harmonization and the global welfare ranking of three different standard-setting regimes:

\footnotetext{
7 The situation where the content of harmonized laws is determined by one particular jurisdiction ('harmonization through delegation') of course need not occur through a formal process of delegation. A particular member jurisdiction may also acquire such authority through a first-mover advantage or sheer political power. Because we do not investigate the origin of how a particular jurisdiction arose as the jurisdiction determining the common standards, we group all these different scenarios under the same heading.
} 
decentralization, harmonization through centralization, and harmonization through delegation. Section 7 concludes.

\section{Related Literature}

Formal normative analyses of the desirability of interventionist legal harmonization are scarce. ${ }^{8}$ Garoupa and Ogus (2006) study how interacting jurisdictions non-cooperatively choose between adjusting and not adjusting their legal orders. Adjusting legal orders gives rise to exogenous benefits from mutual interaction, but also involves bearing likewise exogenous adjustment costs. An interventionist correction aiming to synchronize legal orders is desirable when a noncooperative equilibrium with no adjustment of legal orders is Pareto inferior to an outcome where either or both jurisdictions adjust their legal orders. For the latter to hold, Garoupa and Ogus (2006) show that aggregate adjustment costs must be sufficiently small.

Monheim Helstroffer and Obidzinski (2010) study the desirability of interventionist harmonization of asylum law. Tightening of one jurisdiction's asylum law reduces refugee hosting costs in that jurisdiction, but also spurs an increase in the flow of refugees to another jurisdiction and therefore endogenously increases the latter jurisdiction's refugee hosting cost. Harmonization of asylum laws allows for internalization of this externality, but results in losses due to diminished scope for discretion. Monheim Helstroffer and Obidzinski (2010) clarify when top-down harmonization of asylum law would be socially desirable, as well as what type of asylum law harmonization (fixed standards versus flexible minimum standards) might be the most desirable one.

\footnotetext{
${ }^{8}$ For positive analyses of legal harmonization, see Herings and Kanning (2008), Carbonara and Parisi (2007), and Crettez and Deloche (2006). Van Egteren et al. (2004) analyze strict liability vs. negligence as means of legal harmonization when firms are judgment-proof. Crettez et al. (2009) study the problem of the optimal complexity of harmonized law. Carbonara and Parisi (2009) provide a theoretical inquiry into optimality of different choice-of-law regimes and suggest when state-led (formal) harmonization may or may not coincide with adopted commercial practices.
} 
While both Garoupa and Ogus (2006) and Monheim Helstroffer and Obidzinski (2010) deduce conditions under which interventionist harmonization is socially desirable, they do so in a two-jurisdiction framework with complete and symmetric information. In contrast, Ulph (2000), while still relying on a two-jurisdiction setting, investigates the scope for harmonization of environmental standards if local governments engaging in environmental dumping are privately informed about the local pollution damage costs. Our approach is similar to Ulph's (2000) in that we emphasize informational incompleteness and asymmetry. ${ }^{9}$ Unlike Ulph (2000), however, we explore a more general trade-off inherent in institutional choice in a multi-jurisdiction case. The latter generalization allows us to highlight the thus far neglected role of patterns of jurisdictional interdependence for the scope of interventionist harmonization.

Casella and Feinstein (2002) study the problem of endogenous formation of markets and jurisdictions in a bottom-up (as opposed to top-down, interventionist) process. They show that the sorting of traders in a single jurisdiction (i.e., institutional harmonization) is socially desirable when the markets are poorly integrated. Institutional diversity is socially preferred when markets are perfectly integrated. We, in contrast, show that greater economic integration, which increases the extent of jurisdictional interdependence, could either increase or decrease the desirability of institutional harmonization. More specifically, greater integration increases the relative desirability of interventionist harmonization from the global welfare point of view only when it results in structural asymmetries in the pattern of jurisdictional interdependence.

Finally, Loeper (2009) has independently developed a model in structure similar to ours to contrast non-cooperative policy decentralization with "uniformization". The spirit of a subset

\footnotetext{
${ }^{9}$ Harstad (2007) similarly develops a two-jurisdiction bargaining model with private information about local preferences to study whether regions can benefit by pre-committing themselves to agreements with complete harmonization of public good provision. Harstad (2007) shows that harmonization may be desirable because it does not result in delay which occurs in inter-regional bargaining under decentralization.
} 
of Loeper's (2009: Sec. 4) findings is congruent with a subset of our results (see our Section 6.1) in that decentralization can dominate uniformization when the world is (in our terminology) structurally symmetric. There are, however, several notable differences between Loeper's (2009) and our analysis, both in approach and in scope. First and foremost, Loeper (2009) employs a full-information framework; we explore a framework where local conditions are jurisdictions' private information. Second, when contrasting decentralization with uniformization, Loeper (2009) does not differentiate between alternative means of attaining the latter. We, in contrast, explicitly distinguish between harmonization through centralization and harmonization through delegation. Such approach allows us to characterize a richer set of patterns of interjurisdictional linkages, as well as provide a welfare ranking of three distinct institutional regimes. Third, Loeper (2009) extends his basic framework to investigate the rationale for centralized uniformization in the presence of network effects, an aspect of analysis which is beyond the scope of our paper.

\section{Model Set-Up}

We consider a world of $n$ jurisdictions, indexed by $i \in\{1, \ldots, n\} . n$ could equal two, but, as we show in Sections 5 and 6 below, restricting the analysis to a two-jurisdiction world entails a substantial loss of generality: the full scope for interventionist harmonization can only be determined in a truly multi-jurisdictional setting.

Much like several recent contributions on constitutional design (Lockwood 2002, Besley and Coate 2003; Alesina, Angeloni and Etro 2005), we treat individual jurisdictions are unitary actors (see also Ulph 2000, Garoupa and Ogus 2000). As a consequence, we abstract from the possibility of any kind of factor mobility, (see, e.g., Van den Bergh 2000, Esty and Geradin 2000, Sykes 2000) and choice of law (see, e.g., Ribstein and O'Hara 2000, 2009; Carbonara and 
Parisi 2009) as facilitators of interjurisdictional competition. This simplification, of course, does not imply that we deem such considerations unimportant in delineating the scope for interventionist harmonization. On the contrary, our aim is merely to contribute to the existing body of literature by uncovering an additional, and thus far unexplored, determinant of desirability of top-down harmonization: the role of patterns of jurisdictional interdependence. In doing so, we naturally emphasize the costs of interventionist harmonization due to adoption of one-size-fits-all institutional solutions in diverse local environments (see, e.g., Gomez 2008, Ganuza and Gomez 2008) rather than the costs of top-down harmonization which derive from the loss of benefits from interjurisdictional competition.

The $n$ jurisdictions are assumed to be engaging in a network of multilateral trade and economic relations, which provides a basis for mutual interdependence. A central problem, both at the level of an individual jurisdiction and at the global level, then relates to the choice of suitable legal standards. Laws and regulations should, on one hand, fit the individual jurisdictions' local conditions (see, e.g., Hay and Shleifer 1998, Mukand and Rodrik 2005, Ganuza and Gomez 2008), and, at the same time, allow for reaping of benefits from mutual interdependence which in general increase with harmonization: the use of common legal standards reduces the transaction costs of cross-jurisdictional commerce (see, e.g., Ribstein and Kobayashi 1996, Carbonara and Parisi 2007, Reich 2004). ${ }^{10}$ Accordingly, the payoff of jurisdiction $i$ equals:

$$
V_{i}=-\gamma_{i i}\left(\theta_{i}-L_{i}\right)^{2}-\sum_{j \neq i}^{n} \gamma_{i j}\left(L_{i}-L_{j}\right)^{2}
$$

\footnotetext{
${ }^{10}$ Ribstein and Kobayashi (1996) for example argue that without harmonization, businesses selling their product in different jurisdictions incur "information costs" and greater "litigation costs" because they need to determine what laws apply in individual jurisdictions; they incur "inconsistency costs" because they may need to abide with many different governance rules; and they incur losses from "legal instability" when the law of a foreign jurisdiction applicable to their contract suddenly changes.
} 
In expression (1), $\theta_{i}$ is a random variable, the realization of which summarizes the local socioeconomic conditions in jurisdiction $i$. (We say more about $\theta_{i}$ in Section 4.) $L_{i}$ denotes the choice of the legal standard in jurisdiction $i$, and $L_{j}$ the choice of the legal standard in jurisdiction $j$.

The payoff function (1) captures the central trade-off associated with standard-setting at a jurisdiction's level. A law which is ideally adapted to jurisdiction $i$ 's local conditions $\left(L_{i}=\theta_{i}\right)$ will in general differ from the laws chosen in other jurisdictions. Whenever $L_{i} \neq L_{j}$, jurisdiction $i$ suffers a loss from lack of harmonization with jurisdiction $j \neq i$ in the amount of $\gamma_{i j}\left(L_{i}-L_{j}\right)^{2}$. On the other hand, a law which is fully harmonized with the law of jurisdiction $j\left(L_{i}=L_{j}\right)$ will in general not match jurisdiction $i$ 's local conditions $\left(L_{i} \neq \theta_{i}\right)$, resulting in a loss of $\gamma_{i i}\left(\theta_{i}-L_{i}\right)^{2}$.

The payoff specification (1) highlights the essence of a jurisdiction's choice of suitable legal rules in many areas of both private and public law. Adopting suitable commercial and contract laws, laws of government procurement and procedure, and regulations of customs administration, for example, necessitates that a jurisdiction is attentive to both local specifics and synchronization of its laws with existing international standards in order to materialize any potential gains from economic interdependence (see, e.g., Reich 2004). In contrast, our set-up is less suitable for addressing harmonization in areas of law where a jurisdiction's payoff critically depends on the relative stringency of standards across jurisdictions (as opposed to merely the extent of synchronization with other jurisdictions), and when factor mobility is thus a central concern. With regard to labor and environmental standards, tax law, and competition law, for example, one could argue that jurisdiction $i$, in accordance with (1), incurs costs from lack of harmonization with jurisdiction $j$ when $i$ 's standards are stricter than $j$ 's. When jurisdiction $i$ 's standards are laxer than jurisdiction $j$ 's, however, jurisdiction $i$ might -in contrast with 
specification (1) - in fact benefit from lack of harmonization with jurisdiction $j$ when laxer standards allow jurisdiction $i$ to attract mobile capital and emerge as a winner in the 'race to the bottom' (see, e.g., Van den Bergh 2000, Esty and Geradin 2000, Sykes 2000).

Given payoff function (1), note that the size of jurisdiction $i$ 's loss from lack of harmonization with jurisdiction $j$ depends on the parameter $\gamma_{i j} \geq 0 . \gamma_{i j}$ captures the importance that jurisdiction $i$ attaches to harmonizing its legal standards with the legal standards in jurisdiction $j \neq i . \gamma_{i k}>\gamma_{i l}, k \neq l$, for example, implies that jurisdiction $i$ finds harmonization of its law with the law of jurisdiction $k$ more important than harmonization with the law of jurisdiction $l$, perhaps because jurisdiction $i$ trades with jurisdiction $k$ more than it trades with jurisdiction $l$. Because we normalize $\gamma_{i i}+\sum_{j \neq i} \gamma_{i j} \equiv 1$, the parameter $\gamma_{i i}>0$ measures the importance that jurisdiction $i$ attaches to adapting law to its local conditions relative to harmonization with the rest of the world. The sum $\sum_{j \neq i} \gamma_{i j} \equiv 1-\gamma_{i i}$ hence measures the degree of dependence of jurisdiction $i$ on the rest of the world. When $\gamma_{i i}$ is close to $0, \sum_{j \neq i} \gamma_{i j}$ is close to 1 , implying that jurisdiction $i$ is highly integrated in the global economy. When $\gamma_{i i}$ is close to $1, \sum_{j \neq i} \gamma_{i j}$ is close to 0 , suggesting that jurisdiction $i$ is largely autarkic.

Let $\gamma_{i}=\left[\begin{array}{llll}\gamma_{i 1} & \gamma_{i 2} & \ldots & \gamma_{i n}\end{array}\right]$ be an $n \times 1$ row vector summarizing jurisdiction $i$ 's preferences about the trade-off between matching law to local conditions and harmonizing with other jurisdictions. Then, the $n \times n$ matrix

$$
\boldsymbol{\Gamma} \equiv\left[\begin{array}{c}
\gamma_{1} \\
\boldsymbol{\gamma}_{2} \\
\vdots \\
\gamma_{n}
\end{array}\right]=\left[\begin{array}{cccc}
\gamma_{11} & \gamma_{12} & \ldots & \gamma_{1 n} \\
\gamma_{21} & \gamma_{22} & \cdots & \gamma_{2 n} \\
\vdots & \vdots & \ddots & \vdots \\
\gamma_{n 1} & \gamma_{n 2} & \cdots & \gamma_{n n}
\end{array}\right]
$$

summarizes the pattern of jurisdictional interdependence in the global economy. 
In the analysis in subsequent sections, we highlight several features of $\Gamma$ 's structure. For now, however, observe the following. First, the trace of $\Gamma, \operatorname{tr}(\Gamma) \equiv \sum_{i} \gamma_{i i} \in(0, n)$, captures the extent of global jurisdictional interdependence. When $\operatorname{tr}(\Gamma)$ is close to $n$, the world is largely unintegrated: the jurisdictions care primarily about matching law to local conditions. In contrast, when $\operatorname{tr}(\Gamma)$ is close to 0 , the extent of jurisdictional interdependencies is large: the jurisdictions care primarily about harmonizing their laws and institutions with the laws and institutions of some, or all, other jurisdiction. Second, the elements in the $i$-th row of $\Gamma$ depict jurisdiction $i$ 's preferences for fitting law to its local conditions $\left(\gamma_{i j}\right)$ versus harmonizing with other jurisdictions $\left(\gamma_{i j}\right.$, for all $\left.j \neq i\right)$. Third, the elements of the $i$-th column of $\Gamma$ other than the $i i$-th element are suggestive of the influence that jurisdiction $i$ exerts on the rest of the world. When the rest of the world perceives jurisdiction $i$ as economically important, jurisdictions $j \neq i$ would obtain large benefits from synchronizing its legal standards with the legal standards chosen in jurisdiction $j$. Thus, $\gamma_{j i}^{\prime}$ 's for some, or all, $j \neq i$ will be positive. When, in contrast, jurisdiction $i$ is deemed peripheral, $\gamma_{j i}$ 's will take on values close to zero.

In Sections 4 and 5, we use the above set-up to investigate the aggregate welfare implications of different institutional regimes for setting of global legal standards. In Section 4, we first characterize the benchmark regime of decentralized standard-setting, where jurisdictions choose their respective legal standards non-cooperatively under incomplete information. In Section 5, we explore the desirability of 'top-down' harmonization as an alternative to decentralized standard-setting. We suggest two alternative means of attaining full harmonization of global legal standards: harmonization through centralization, and harmonization through delegation. We contrast these two top-down approaches of implementing full harmonization with 
decentralized standard-setting, as well as with each other. In Section 6, we provide a global welfare ranking of the three different legal standard-setting regimes and delineate the scope for interventionist harmonization.

\section{Decentralized Legal Standard-Setting}

Under decentralization, jurisdictions choose their legal standards simultaneously and independently. We assume that $\theta_{i}^{\prime}$ s are drawn independently from a common distribution with zero mean and a variance, which we normalize to one. ${ }^{11}$ The values of $\theta_{i}$ 's are realized at time 1. The realization of $\theta_{i}$ is private information of jurisdiction $i$ : while every jurisdiction knows its own local conditions, it does not know the local conditions prevailing in other jurisdictions. All jurisdictions, however, know the common distribution from which $\theta_{i}$ 's are drawn. Jurisdictions choose their legal standards simultaneously and non-cooperatively at time 2 . The payoffs are realized at time 3 .

The jurisdictions setting their legal standards at time 2 therefore engage in a static game of incomplete information. We search for the Bayesian-Nash equilibrium, where we write jurisdiction $j$ 's equilibrium strategy as $L_{j}\left(\theta_{j}\right), j \in\{1, \ldots, n\}$. Jurisdiction $i$ therefore chooses $L_{i}$ to maximize

$$
V_{i}=-\gamma_{i i}\left(\theta_{i}-L_{i}\right)^{2}-\mathrm{E}\left[\sum_{j \neq i} \gamma_{i j}\left(L_{i}-L_{j}\left(\theta_{j}\right)\right)^{2}\right]
$$

where the expectation is taken over all $\theta_{j}^{\prime} \mathrm{s}, j \neq i$. Simplifying the resulting first-order condition gives:

$$
\gamma_{i i} \theta_{i}-L_{i}+\sum_{j \neq i} \gamma_{i j} \mathrm{E}_{\theta_{j}}\left[L_{j}\left(\theta_{j}\right)\right]=0
$$

\footnotetext{
11 The assumption about independently and identically distributed $\theta_{i}^{\prime}$ s implies that jurisdictions are ex ante homogenous in terms of their local conditions.
} 
Upon taking the expectation of (4) with respect to $\theta_{i}$, we obtain:

$$
-\mathrm{E}_{\theta_{i}}\left[L_{i}\left(\theta_{i}\right)\right]+\sum_{j \neq i} \gamma_{i j} \mathrm{E}_{\theta_{j}}\left[L_{j}\left(\theta_{j}\right)\right]=0 ; i \in\{1, \ldots, n\}
$$

As we show in Appendix A, the system (5) has a unique solution of $\mathrm{E}_{\theta_{i}}\left[L_{i}\left(\theta_{i}\right)\right]=0$ for all $i \in\{1, \ldots, n\}$. From (4) it then follows that, in the equilibrium under decentralized standard-setting, $L_{i}^{D}=\gamma_{i i} \theta_{i}$, for $i \in\{1, \ldots, n\}$. Intuitively, the more jurisdiction $i$ cares about fitting law to own local conditions (as opposed to synchronizing its legal standards with the rest of the world), the more jurisdiction $i$ 's equilibrium legal standard reflects $i$ 's local conditions, rather than $i$ 's expectation about the average global conditions (which, because $\mathrm{E} \theta_{i}=0$, equal 0 ). ${ }^{12}$ In contrast, if jurisdiction $i$ cares about synchronizing its standards with the rest of the world, then $\gamma_{i i}$ is close to 0 , and $L_{i}^{D}$ is close to 0 . When $\gamma_{i i}$ is close to 0 for all $i \in\{1, \ldots n\}$, decentralized standard-setting therefore endogenously results in convergence of institutional solutions across jurisdictions even in the presence of ex-post heterogeneity of local conditions. ${ }^{13}$

Given that the values of $\theta_{i}^{\prime}$ s are realized at time 1 (see above), the jurisdictions' local conditions are unknown before time 1. The ex-ante expected payoff of jurisdiction $i$ under decentralization therefore equals:

$$
\mathrm{E} V_{i}^{D}=-\mathrm{E}\left[\gamma_{i i}\left(\theta_{i}-\gamma_{i i} \theta_{i}\right)^{2}+\sum_{j \neq i} \gamma_{i j}\left(\gamma_{i i} \theta_{i}-\gamma_{j j} \theta_{j}\right)^{2}\right]
$$

where the expectation is taken over all $\theta_{i}^{\prime} \mathrm{s}, i \in\{1, \ldots, n\}$. Applying the expected value, (6) gives:

$$
\mathrm{E} V_{i}^{D}=-\gamma_{i i}\left(1-\gamma_{i i}\right)^{2}-\left(1-\gamma_{i i}\right) \gamma_{i i}^{2}-\sum_{j \neq i} \gamma_{i j} \gamma_{j j}^{2}
$$

\footnotetext{
${ }^{12}$ It can be shown, for example, that with $n=2$ and $\mathrm{E} \theta_{1}=\mathrm{E} \theta_{1}=\mu$, the equilibrium standard of jurisdiction $i$ equals $L_{i}=\gamma_{i i} \theta_{i}+\left(1-\gamma_{i i}\right) \mu$.

${ }^{13}$ The idea that harmonization could be a result of a bottom-up decentralized process (as opposed to a centralized, interventionist one) is of course a familiar one (see, e.g., Ogus 1999, Van den Bergh 2000, Smits 2002). Garoupa and Ogus (2006) and Herings and Kanning (2008), for example, formally arrive at a similar conclusion in a twojurisdiction framework with complete information and exogenous costs and benefits from law.
} 
The first term in (7) are jurisdiction $i$ 's ex ante expected losses due to the fact that jurisdiction $i$ finds it optimal to choose standards which do not fully reflect its local conditions. The second and the third term are jurisdiction $i$ 's expected losses from lack of harmonization with other jurisdictions. Grouping the first and the second term in (7) together, we can further write

$$
\mathrm{E} V_{i}^{D}=-\gamma_{i i}\left(1-\gamma_{i i}\right)-\sum_{j \neq i} \gamma_{i j} \gamma_{j j}^{2}
$$

Jurisdictions are assumed to possess equal weight in accounting for aggregate welfare. ${ }^{14}$ The ex-ante expected global welfare (global welfare, in short) under decentralization then equals:

$$
\mathrm{E} W^{D} \equiv \sum_{i} \mathrm{E} V_{i}^{D}=-\sum_{i} \gamma_{i i}\left(1-\gamma_{i i}\right)-\sum_{i} \sum_{j \neq i} \gamma_{i j} \gamma_{j j}^{2}
$$

which, upon observing that $\sum_{i} \sum_{j \neq i} \gamma_{i j} \gamma_{j j}^{2} \equiv \sum_{i} \gamma_{i i}^{2} \sum_{j \neq i} \gamma_{j i}$, we can re-write as:

$$
\mathrm{E} W^{D}=-\sum_{i} \gamma_{i i}\left(1-\gamma_{i i}\right)-\sum_{i} \gamma_{i i}^{2} F_{i}
$$

In expression (10), $F_{i} \equiv \sum_{j \neq i} \gamma_{j i}$ is the sum of all but the $i i$-th element $\left(\gamma_{i i}\right)$ of the $i$-th column of matrix $\Gamma$ (see expression (2)). The sum $F_{i} \equiv \sum_{j \neq i} \gamma_{j i}$ plays a central role in our subsequent analysis: it captures the joint interest of all jurisdictions other than $i$ to synchronize their respective legal standards with the legal standards of jurisdiction $i$. Accordingly, we introduce the following definition:

Definition 1: The sum $F_{i} \equiv \sum_{j \neq i} \gamma_{j i} \geq 0$ is referred to as the degree of focality of jurisdiction $i$. Jurisdiction $i$ said to be focal if $F_{i}>1$, and non-focal if $F_{i} \leq 1$.

\footnotetext{
${ }^{14}$ This assumption simplifies the algebra and enhances tractability. Extending the model to allow for jurisdictions' weights in aggregate welfare to differ preserves all qualitative aspects of our results, but also introduces considerations about the effects of constituency size of individual jurisdictions. Proof of this point is available upon request.
} 
A focal jurisdiction is therefore one that provides a strong pull for two or more other jurisdictions which would obtain large benefits from synchronizing their standards with the focal jurisdiction. According to Definition 1, more than one jurisdiction can be focal, but not all jurisdictions can be focal. ${ }^{15}$ It can be the case, however, that all jurisdictions are non-focal.

Observe from expression (10) that the global welfare under decentralization is a sum of two terms. The first term in (10) follows directly from the first term in (8) and captures the ex ante expected global losses due to the impact of lack of information about $i$ 's local conditions on $i$ 's own expected payoff. The second term in (10) in contrast captures the global welfare effect of the lack of information of other jurisdictions about $i$ 's local conditions through affecting the ability of other jurisdictions to synchronize their legal standards with the legal standards chosen by jurisdiction $i$. If, for a given $\gamma_{i i}>0$, jurisdiction $i$ is non-focal (e.g., $F_{i}$ is close to zero), the rest of the world's benefits from synchronizing legal standards with the legal standards of jurisdiction $i$ are small. In this case, the lack of information about $i$ 's local conditions does not affect the rest of the world, but rather impacts the expected global welfare only through the direct effect on $i$ 's own ex ante payoff (see the first term in (10)). In contrast, when jurisdiction $i$ is focal $\left(F_{i}>1\right)$, other jurisdictions are in the aggregate dependent on jurisdiction $i$ and would therefore obtain large benefits from synchronizing their legal standards with the legal standards of jurisdiction $i$. In this case, the uncertainty about the local conditions in jurisdiction $i$ precludes other jurisdictions from synchronizing their standards with the standards implemented in jurisdiction $i$. Because the focal jurisdiction ignores the external effect of its standards on the rest of the world, decentralized standard-setting may lead to large global welfare losses.

\footnotetext{
${ }^{15}$ To see this, note that $\sum_{i} F_{i}=\sum_{i} \sum_{j \neq i} \gamma_{j i}=n-\sum_{i} \gamma_{i i}<n$.
} 


\section{Harmonization of Global Legal Standards}

To formalize the distinction between decentralized standard-setting and top-down harmonization of global legal standards, we first add an extra, constitutional stage to the timing of events described in Section 4. The constitutional stage at time 0 determines the institutional regime for legal standard-setting when there is no information yet about the local conditions prevailing in individual jurisdictions (i.e., when $\theta_{i}$ 's are unknown). At time 0 , all that is known is that $\theta_{i}$ 's will be drawn independently from a common distribution with zero mean and variance equal to one. At time 1 , the values of $\theta_{i}$ s are realized and each jurisdiction $i$ learns about its own $\theta_{i}$. If decentralization $(D)$ is chosen at the constitutional stage at time 0 , the jurisdictions choose their legal standards simultaneously and independently at time 2, as described in Section 4.

Alternatively, global legal standards may be harmonized top down, with an exogenous intervention. We focus on two means of top-down harmonization of global legal standards. Under harmonization through centralization $(H C)$, a global central authority chooses a single legal standard at time 0 , before the values of $\theta_{i}$ 's are realized, maximizing the expected global welfare. ${ }^{16}$ But harmonization may also occur when the common global standard is determined by one particular jurisdiction only-a scenario which we refer to as harmonization through delegation $(H d)$. In this case, at the constitutional stage at time 0 , the authority to determine the common global legal standard is allocated to a particular jurisdiction. ${ }^{17}$ The jurisdiction allocated the lawmaking powers chooses its preferred legal standard at time 2, after having learned its

\footnotetext{
${ }^{16}$ In this paper, we do not study the possibility that the supra-jurisdictional authority would provide monetary incentives for jurisdictions to correctly reveal their private information about local conditions. In the latter case, clearly, centralization in general will not imply full harmonization. See Ulph (2000) for an analysis of the welfare losses that arise under harmonization through centralization relative to the first-best centralized policy, which involves a design of incentives for jurisdictions to reveal their private information, in a two-jurisdiction setting with environmental dumping.

${ }^{17}$ We do not explain how a particular jurisdiction is chosen as the jurisdiction setting the common legal standard. See also footnote 7 above.
} 
local conditions at time 1 . The rest of the world then adopts the thereby determined legal rules. The payoffs in any of the institutional regimes are realized at time 3.

\subsection{Harmonization through Centralization}

When harmonization is implemented through centralization, the global central authority chooses a single legal standard, $L$, at the constitutional stage, before $\theta_{i}^{\prime}$ s are realized, maximizing the expected global welfare, $-\mathrm{E} \sum_{i} \gamma_{i i}\left(\theta_{i}-L\right)^{2}$. Solving the maximization problem results in the global legal standard $L^{H C}=0 .{ }^{18}$ The expected payoff of jurisdiction $i$ under harmonization through centralization equals $\mathrm{E} V_{i}^{H C}=-\gamma_{i i}$. The resulting expected global welfare then equals

$$
\mathrm{E} W^{H C} \equiv \sum_{i} \mathrm{E} V_{i}^{H C}=-\sum_{i} \gamma_{i i}
$$

Under harmonization through centralization, a common legal standard is imposed on all jurisdictions which are ex post (after $\theta_{i}^{\prime}$ s are realized) heterogeneous in terms of their local conditions. Thus, the expected global losses increase with the extent to which the jurisdictions care about matching legal standards to their local conditions. The greater the extent of jurisdictional interdependence (implying that the diagonal elements of $\Gamma$ are close to zero), the smaller are the expected losses from imposing a single global standard in an otherwise ex post heterogeneous world.

Under what conditions is harmonization through centralization $(H C)$ preferred to decentralized standard-setting $(D)$ from the global welfare point of view? Comparing (10) and (12) gives:

\footnotetext{
${ }^{18}$ Observe that in our framework, where $\theta_{i}^{\prime}$ s are drawn from a common distribution and where transfers from the supra-jurisdictional authority to individual jurisdictions (to reveal private information about local conditions) are precluded, the global central authority would choose full harmonization even if promulgating different standards for different jurisdictions were an option.
} 
Lemma 1: $\mathrm{E} W^{D}\left\{\begin{array}{l}> \\ \overline{=} \\ <\end{array}\right\} \mathrm{E} W^{H C}$ if and only if $\sum_{i} \gamma_{i i}^{2}\left(1-F_{i}\right)\left\{\begin{array}{l}> \\ \overline{\overline{<}}\end{array}\right\} 0$.

To understand Lemma 1, note that under decentralized standard-setting $(D)$, every jurisdiction $i$ ignores the effect of their own standards on other jurisdictions, who may want to synchronize their standards with the standards of jurisdiction $i$. Ceteris paribus, the relative attractiveness of harmonization through centralization $(H C)$ then depends on the pattern of jurisdictional interdependence. If none of the jurisdictions are focal $\left(F_{i}<1\right.$ for all $\left.i \in\{1, \ldots, n\}\right)$, the fact that under $D$ every jurisdiction $i$ ignores the externality that it imposes on others, will, on the aggregate, result in limited aggregate losses from lack of mutual harmonization, suggesting that $D$ dominates $H C .{ }^{19}$ On the other hand, if there exists one or more focal jurisdictions $\left(F_{i}>1\right.$ for some $i \in\{1, \ldots, n\})$, implying that other jurisdictions care considerably about synchronizing their standards with standards of jurisdiction $i$, then, as suggested in Section 4, aggregate losses under $D$ may be substantial. As a result, $H C$ may be a better institutional solution than $D$ from the global welfare point of view.

Importantly, for $H C$ to dominate $D$ from the global welfare point of view, focal jurisdictions must care sufficiently about its own local conditions. If jurisdiction $i$ is focal, but $i$ cares primarily about synchronizing its standards with other jurisdictions ( $\gamma_{i i}$ is close to 0$)$, then the scope for $H C$ to dominate $D$ from the global welfare point of view is small. The reason is that when the focal jurisdiction $i$ benefits from synchronizing its standards with other jurisdictions $\left(\gamma_{i i}\right.$ is close to 0 ), $L_{i}^{D}$ is close to 0 (see Section 4). As this is common knowledge, other jurisdictions'

19 Observe, in particular, that when $\Gamma$ is symmetric (i.e., $\gamma_{i j}=\gamma_{j i}$ for $i \neq j$ ), then, because $F_{i} \equiv \sum_{j \neq i} \gamma_{j i}=\sum_{j \neq i} \gamma_{i j}=1-\gamma_{i i}<1$, there exist no focal jurisdictions, implying that $\mathrm{E} W^{D}>\mathrm{E} W^{H C}$. This result is in spirit congruent with Proposition 2 in Loeper (2009). Loeper (2009), however, among other differences, arrives at his result in a framework with full (rather than asymmetric) information; see also discussion in our Section 6.1. 
lack of information about $i$ 's local conditions does not pose a significant problem: those jurisdictions that would obtain large benefits from synchronizing their standards with the standards of the focal jurisdiction are still able to do so. With $i$ focal and $\gamma_{i i}$ close to $0, D$ therefore dominates $H C$ from the global welfare point of view even though the aggregate losses due to the misfit of law to local conditions under $H C$ are relatively small.

In contrast, if the focal jurisdiction primarily strives to match its law to its own local conditions $\left(\gamma_{i i}\right.$ is close to 1$)$, then, as shown in Section $4, L_{i}^{D}$ closely reflects $i$ 's local conditions $\left(\theta_{i}\right)$. In this case, other jurisdictions' lack of information about the focal jurisdiction's local conditions prevents these jurisdictions from synchronizing their standards with the standards of the focal jurisdiction. The lack of information about the focal jurisdiction's local conditions is in this case very costly from the global welfare point of view. At the same time, the aggregate costs due to the misfit of law to local conditions under $H C$ are at the same time relatively small. Thus, $H C$ can dominate $D$ from the global welfare point of view, creating scope for interventionist harmonization.

Finally, Lemma 1 provides direct evidence on why restricting the analysis to a twojurisdiction setting in our framework does not come without loss of generality (as suggested in the Introduction). In a two-jurisdiction world, by Definition 1, there exist no focal jurisdictions $\left(F_{1}=\gamma_{21} \equiv 1-\gamma_{22}<1\right.$, and $\left.F_{2}=\gamma_{12} \equiv 1-\gamma_{11}<1\right)$. Thus, by Lemma 1 , in a two-jurisdiction world (a set-up typically investigated in the literature; see Section 2) $D$ always welfare dominates $H C$ - a conclusion which, as we have shown, does not extend to a more realistic multijurisdiction set-up. 


\subsection{Harmonization through Delegation}

When harmonization of global legal standards proceeds through allocation of lawmaking authority to jurisdiction $k$, the latter, upon learning its own local conditions $\left(\theta_{k}\right)$ at time 1 , chooses a unique global legal standard to maximize its payoff, $-\gamma_{k k}\left(\theta_{k}-L_{k}\right)^{2}$. The resulting legal standard, which is adopted by the rest of the world at time 2, equals $L^{H d}=\theta_{k}$. Thus, the expected payoff of jurisdiction $i$ under harmonization through delegation is $\mathrm{E} V_{i}^{H d}=-2 \gamma_{i i}$ if $i \neq k$, and $\mathrm{E} V_{k}^{H d}=0$. The resulting expected global welfare under harmonization through delegation equals

$$
\mathrm{E} W^{H d} \equiv \sum_{i} \mathrm{E} V_{i}^{H d}=-\sum_{i \neq k} 2 \gamma_{i i}
$$

As it is relatively straightforward, we first compare the regime of harmonization through delegation $(H d)$ with harmonization through centralization $(H C)$. The comparison of $(11)$ and (12), where the index $k$ denotes the jurisdiction allocated the lawmaking authority under $H d$, yields:

Lemma 2: $\mathrm{E} W^{H d}\left\{\begin{array}{l}\geq \\ \underset{<}{<}\end{array}\right\} \mathrm{E} W^{H C}$ if and only if $\gamma_{k k}-\sum_{i \neq k} \gamma_{i i}\left\{\begin{array}{l}\geq \\ \overline{<}\end{array}\right\} 0$,

According to Lemma 2, global welfare is greater under $H d$ than under $H C$ if and only if jurisdiction $k$ 's extra benefit from the perfect fit of law to its local conditions under $H d$ relative to $H C\left(\mathrm{E} V_{k}^{H d}-\mathrm{E} V_{k}^{H C}=\gamma_{k k}>0\right)$ exceeds the aggregate extra losses due to misfit under $H d$ relative to $H C$ incurred by all jurisdictions other than $k\left(\mathrm{E} V_{i}^{H d}-\mathrm{E} V_{i}^{H C}=-\gamma_{i i}<0\right.$ for $\left.i \neq k\right)$. In other words, global welfare is greater under $H d$ than under $H C$ if the concern for local conditions of the jurisdiction with the lawmaking authority to set the common standard under $H d$ outweighs the aggregate degree of concern of all other jurisdictions for their respective local conditions. We therefore introduce our second definition: 
Definition 2: Let $A_{j} \equiv \gamma_{j j}-\sum_{i \neq j} \gamma_{i i}$. Jurisdiction $j$ is said to be autonomous if $A_{j}>0$, and nonautonomous otherwise.

According to Definition 2, at most one jurisdiction can be autonomous. Moreover, the existence of an autonomous jurisdiction is equivalent to harmonization through delegation (to the autonomous jurisdiction) yielding greater global welfare than harmonization through centralization. Given Definitions 1 and 2, we also describe a jurisdiction which is both autonomous and deemed focal by the rest of the world:

Definiton 3: Jurisdiction $j$ is said to be dominant if it is both focal and autonomous, and nondominant otherwise.

A dominant jurisdiction is one that both provides a strong pull for two or more other jurisdictions, which would obtain large benefits from synchronizing their standards with the dominant jurisdiction, and is at the same time relatively independent of the rest of the world. Because at most one jurisdiction in the world can be autonomous (see Definition 2), by implication, at most one jurisdiction can be dominant. (Note again that by Definition 1 a dominant jurisdiction can only arise in a multi-jurisdiction setting.)

Finally, we investigate how harmonization through delegation to jurisdiction $k(H d)$ compares with decentralized standard-setting $(D)$. The comparison of (10) and (12) yields

$$
\mathrm{E} W^{H d}-\mathrm{E} W^{D} \equiv\left(\mathrm{E} W^{H d}-\mathrm{E} W^{H C}\right)-\left(\mathrm{E} W^{D}-\mathrm{E} W^{H C}\right)=\left(\gamma_{k k}-\sum_{j \neq k} \gamma_{j j}\right)-\sum_{j} \gamma_{j j}^{2}\left(1-F_{j}\right)
$$

which in turn implies:

Lemma 3: $\mathrm{E} W^{H d}\left\{\begin{array}{l}\geq \\ \underset{<}{<}\end{array}\right\} \mathrm{E} W^{D}$ if and only if $A_{k}-\gamma_{k k}^{2}\left(1-F_{k}\right)-\sum_{j \neq k} \gamma_{j j}^{2}\left(1-F_{j}\right)\left\{\begin{array}{l}\geq \\ \underset{<}{<}\end{array}\right\}$.

A comparison between $H d$ and $D$ is therefore less straightforward than the comparison between $H d$ and $H C$ (Lemma 2). In general, Lemma 3 suggests that harmonization through delegation to 
jurisdiction $k$ can yield higher global welfare than decentralization under three general scenarios:

(i) when $k$ is dominant, (ii) when $k$ is focal but not autonomous, and (iii) when there are no focal jurisdictions in the world, but the degree of $k$ 's autonomy is large (so that $A_{k}$ is large).

\section{Global Welfare Ranking of Regimes and the Scope for Interventionist Harmonization}

Sections 4 and 5 have described and contrasted the regime of decentralized standard-setting with two means of harmonization of global legal standards: through centralization and through delegation. Under what conditions is interventionist harmonization desirable from the global welfare point of view? And more generally, can we identify conditions under which any of the three institutional regimes is globally optimal? In this section, we shed light on these questions by examining the role of patterns of jurisdictional interdependence as implied by the structure of the matrix $\Gamma$ (expression (2)).

Lemmas 1-3 together with Definitions 1-3 readily suggest the following result:

\section{Proposition:}

(i) When there are no focal and no autonomous jurisdictions, the expected global welfare is greatest under decentralization $(D)$.

(ii) When there are no autonomous jurisdictions, but there exists one or more focal jurisdictions, the expected global welfare is greatest either under decentralization (D) or under harmonization through centralization (HC) as dictated by Lemma 1.

(iii) When there exists an autonomous jurisdiction, which may or may not be dominant, the expected global welfare is greatest either under decentralization (D) or under harmonization through delegation to the autonomous (or dominant) jurisdiction (Hd) as dictated by Lemma 3.

Definitions 1-3 spell out the precise nature of the patterns of jurisdictional interdependence that we examine. More loosely speaking, however, when there exist no focal, no autonomous, and hence no dominant, jurisdictions, the world can be described as structurally 
symmetric. $^{20}$ In the opposite case-when there exist one or more focal jurisdictions, an autonomous jurisdiction, or even a dominant jurisdiction — the world may be referred to as being structurally asymmetric.

Accordingly, part (i) of the Proposition suggests that in a structurally symmetric world, there exists no reason to pursue top-down harmonization of global legal standards: the regime of decentralized standard-setting unambiguously yields greater expected aggregate welfare than both harmonization through centralization and harmonization through delegation. There are two notable implications of this result. First, recall that in our framework, the jurisdictions are ex ante (at time 0) homogeneous when it comes to their local conditions. Suppose, in addition, that jurisdictions are homogeneous with respect to their preferences about matching law to local conditions versus harmonizing with other jurisdictions: $\gamma_{i i}=\gamma_{j j}$ and $\gamma_{i j}=[1 /(n-1)]\left(1-\gamma_{i i}\right)$ for all $i, j \in\{1, \ldots, n\}$. In this case, the above Proposition suggests that even with full ex ante homogeneity (that is, both with respect to ex ante local conditions and local preferences) and existence of cross-jurisdictional externalities, a decentralized institutional regime outperforms top-down harmonization through centralization or delegation.

The above result stands in contrast to conclusions from much of the literature on institutional harmonization inspired by the theory of federalism. A robust normative prediction from the theory of federalism is that, ceteris paribus, the desirability of institutional decentralization decreases with the prevalence of cross-jurisdictional spillovers and the degree of local homogeneity (see, e.g., Oates 1974, Alesina, Angeloni and Schuknecht 2005; Van den Bergh 2000). Our analysis, in contrast, suggests that, in the presence of cross-jurisdictional

\footnotetext{
${ }^{20}$ The scenario where there are no focal and no autonomous jurisdictions (and hence no dominant jurisdiction) does not require symmetry of the $\Gamma$ matrix (i.e., that $\gamma_{i j}=\gamma_{j i}$ for $i \neq j$ ). On the other hand, a symmetric $\Gamma$ implies that there are no focal and no autonomous jurisdictions (and hence no dominant jurisdiction).
} 
externalities and ex ante homogeneity in local conditions, the desirability of decentralized standard-setting actually increases with homogeneity of local preferences across jurisdictions. Intuitively, the reason is that, in our framework, homogeneity of local preferences about local adaptation versus harmonization of legal standards eliminates structural asymmetries in the pattern of cross-jurisdictional interdependence, which in turn mitigates the aggregate costs from externalities arising under decentralized standard-setting.

Second, in our framework, greater global integration (e.g., $\gamma_{i i}$ decreases for all $i$ ), and thus a greater degree of jurisdictional interdependence, by no means necessitates interventionist harmonization from the perspective of the aggregate welfare. Our analysis therefore resonates with the perspective of Casella and Feinstein (2002) who have also argued analytically that greater market integration need not be accompanied by top-down harmonization of institutions. ${ }^{21}$ In contrast to Casella and Feinstein (2002), however, we show that it is not the extent, but rather the pattern of global integration that affects the desirability of interventionist harmonization from the aggregate welfare point of view, as made explicit in parts (ii) and (iii) of the Proposition.

Our conclusions following from part (i) of the Proposition closely resonate with the spirit of a subset of findings in Loeper (2009: Sec.4). Loeper (2009) delineates the scope for noncooperative decentralization as an alternative to "uniformization" in a framework similar to ours (see Section 2 of our paper), but under the assumption of full information. When viewed jointly, the two papers therefore complement each other in suggesting a forceful prediction: an interdependent but (in our terminology) structurally symmetric world does not require top-down

\footnotetext{
${ }^{21}$ Casella and Feinstein (2002) in fact show that the social desirability of institutional harmonization decreases with the degree of economic integration (see their Proposition 4). In their framework with endogenous formation of markets and jurisdictions, the possibility of selecting an institutional arrangement better tailored to specific needs (institutional diversity) compensates for higher taxes and transaction costs only when the extent of economic integration is sufficiently high. When the extent of economic integration is low, in contrast, Casella and Feinstein (2002) show that institutional harmonization is socially optimal.
} 
harmonization, regardless of whether the local conditions are jurisdictions' private information (as in our framework) or not (as in Loeper (2009)). ${ }^{22}$

Part (ii) of our Proposition suggests that harmonization through centralization may be the globally optimal institutional regime under two conditions. First, the pattern of jurisdictional interdependencies must be such that there exists no jurisdiction which is, in comparison with other jurisdictions, autonomous from the rest of the world (see Lemma 2 and the discussion following it). Second, there should in addition exist one or more focal jurisdictions, in which case the lack of internalization of externalities under decentralized standard-setting may give rise to significant aggregate welfare losses. Note, however, that the above conditions are jointly only necessary, but not sufficient for harmonization through centralization to yield the greatest expected aggregate welfare. According to Lemma 1, for harmonization through centralization to also welfare dominate decentralization, the focal jurisdiction(s) must in addition be sufficiently concerned about implementing legal standards that match its local conditions (i.e., if $i$ is focal, $\gamma_{i i}$ must not be too small). It is in this case that the other jurisdictions' lack of knowledge about the focal jurisdiction's local conditions prevents them from reaping the benefits from synchronizing their laws with the laws of the focal jurisdictions. Because under decentralization the focal jurisdiction ignores the external effect of its laws on the rest of the world, the expected welfare losses under decentralization are then so significant that they outweigh the aggregate costs of misfit due to the one-size-fits-all solutions imposed under harmonization through centralization.

\footnotetext{
${ }^{22}$ Note, again, that a structurally symmetric world in our terminology does not require a symmetric $\Gamma$. Moreover, a symmetric $\Gamma$ in our set-up does not imply that decentralization $(D)$ is necessarily the best institutional regime; harmonization through delegation $(H d)$ can yield greatest global welfare even under a symmetric $\Gamma$-see Appendix B for a numerical example. In contrast, in Loeper's (2009) set-up with full information, a symmetric matrix of interjurisdictional linkages, because of a different normalization of parameters, also implies homogeneity of preferences across jurisdictions and dominance of decentralization over uniformization (see Proposition 2 in Loeper (2009)).
} 
Part (iii) of the Proposition suggests that harmonization through centralization is never the globally optimal institutional regime when a focal jurisdiction is also autonomous (so that a focal jurisdiction is in fact dominant—see Definition 3), or when there are no focal jurisdictions but there exists an autonomous jurisdiction. Under these circumstances, the expected aggregate welfare is greatest either under harmonization through delegation or under decentralization, depending on the exact pattern of jurisdictional interdependence.

Part (iii) of the Proposition allows us to reflect upon an interpretation of the process of legal harmonization recently put forth by Herings and Kanning (2008). Drawing on a twojurisdiction, complete information model with exogenous costs and benefits from law, Herings and Kanning (2008) predict that the substantive content of harmonized rules is naturally dictated by the jurisdiction which is the economically relatively more important one from the perspective of its economic partner. The reason is that the economically less important jurisdiction is, because of relatively smaller switching costs, more willing to adopt its laws to the laws of the economically important jurisdiction than vice versa. This theory, according to Herings and Kanning (2008), for example helps rationalize the leading role of the United States in the process of drafting of the United Nations' Convention for the International Sale of Goods.

Our analysis naturally complements Herings and Kanning's (2008). While Herings and Kanning (2008) focus on the positive aspect of institutional harmonization, we emphasize the normative angle, suggesting when harmonization through allocation of lawmaking authority to a particular jurisdiction may be desirable from the aggregate welfare point of view. In particular, our results suggest that when there exist a dominant (i.e., autonomous and focal) jurisdiction, harmonization through allocation of lawmaking authority to that dominant jurisdiction may 
indeed be the optimal institutional regime (see part (iii) of the Proposition). ${ }^{23}$ Hence, while the economically 'dominant' jurisdiction according to Herings and Kanning (2008) naturally assumes the leading role in the process of determining the content of harmonized laws, our analysis suggests that assigning a leading role to such a jurisdiction might in fact also be desirable from the global welfare point of view. ${ }^{24}$

\section{Conclusion}

This paper departs from the existing formal literature on legal harmonization by examining the scope for top-down harmonization of legal standards across multiple, mutually interdependent jurisdictions which strive to fit law to their local conditions as well as synchronize it with other jurisdictions. In a setting where jurisdictions are privately informed about their local conditions, we contrast the regime of decentralized standard-setting with harmonization through centralization and harmonization through allocation of lawmaking powers to a particular jurisdiction.

In delineating the scope for interventionist harmonization-which, as we have shown, can be adequately determined only in a truly multi-jurisdictional setting—our results suggest that it is not the extent, but rather the pattern, of jurisdictional interdependence that determines whether interventionist harmonization is desirable or not. When there exist no notable structural asymmetries in the pattern of jurisdictional interdependence (that is, when there exist no focal, autonomous, or dominant jurisdictions), decentralized standard-setting unambiguously

\footnotetext{
${ }^{23}$ Note, however, that the existence of a dominant jurisdiction in our framework does not necessarily imply that global welfare is greatest under harmonization through delegation to the dominant jurisdiction. Instead, the regime of decentralized standard-setting can still yield greater expected global welfare (see part (iii) of the Proposition). A numerical example in Appendix $C$ illustrates this point.

${ }^{24}$ Importantly, the global optimality of harmonization through delegation of lawmaking authority to a 'dominant' jurisdiction $(H d)$ is not due to the dominant jurisdiction's constituency size: in our set-up, all jurisdictions have equal weight in social welfare and 'dominance' is strictly a feature of a specific pattern of jurisdictional interdependence; see Definition 3.
} 
dominates interventionist harmonization from the aggregate welfare point of view. Thus, greater jurisdictional interdependence $-a$ distinguishing feature of globalization-per se by no means necessitates interventionist harmonization (see also Loeper 2009: 20).

We show that top-down harmonization may therefore be desirable only in the presence of structural asymmetries in the pattern of interjurisdictional linkages-when there exists one or more 'focal' jurisdictions, or when a particular jurisdiction (which may, but need not be focal) is 'autonomous' from the rest of the world. In the presence of structural asymmetries in the pattern of jurisdictional interdependence, the fact that every jurisdiction lacks information about the local conditions in other jurisdictions may result in substantial aggregate welfare losses due to the inability of the world to synchronize its laws. Interventionist harmonization is then desirable when the aggregate losses from lack of harmonization exceed the aggregate losses due to the misfit of uniform legal solutions to local realities. We further show under what circumstances interventionist harmonization should proceed through centralization or through delegation to an autonomous, or a 'dominant', jurisdiction.

We conclude this paper with several remarks about the caveats of our analysis. First, our approach follows the existing formal literature on interventionist legal harmonization (Garoupa and Ogus 2006, Monheim Helstroffer and Obidzinski 2010, Ulph 2000) in that our view of harmonization is solely one of a corrective intervention: our analysis abstracts from all complications arising from the necessarily political nature of top-down harmonization. Yet we should not forget that a corrective intervention, orchestrated by a supra-jurisdictional body, may under political pressures easily result in biased content of harmonized laws, as well as induce sizeable monitoring, enforcement, and other administrative costs (Garoupa and Ogus 2006, Sec.4). All of the above reasons reduce the attractiveness of top-down harmonization. Moreover, 
harmonization may not even be attainable if jurisdictions, whose welfare could decrease because of harmonization, can opt out of the process (see, e.g., Hoel 1992).

Second, our goal has been to illuminate the thus far neglected role of patterns of jurisdictional interdependence for interventionist harmonization from a normative viewpoint. To this end, and to ensure tractability, we have kept our theoretical framework as simple as possible, assuming that the jurisdictions' local conditions are drawn from a common distribution, as well as that they are stochastically independent. To the extent that jurisdictional interdependence can also be understood as "co-movement" of jurisdictions' local conditions, however, future work could attempt to re-examine the validity of our conclusions in a set-up where local conditions are correlated.

Finally, the problem of harmonization versus decentralization of legal standards across jurisdictions is in many ways akin to the problem of centralized versus decentralized coordination of an organization's subdivisions studied in the theory of organizations (Alonso et al. 2008, Rantakari 2008). The latter theory has drawn on the cheap-talk literature to emphasize the role of strategic information transmission for optimal organization design. To the extent that strategic communication is possible both among multiple jurisdictions, as well as between jurisdictions and the suprajurisdictional authority (see, e.g., Knill and Lenschow 2005), future work could attempt to study the desirability of top-down harmonization in this light. 


\section{References}

Alesina, Alberto, Ignazio Angeloni, and Ludger Schuknecht. 2005. "What Does the European Union Do?" Public Choice, 123:3, 275-319.

Alesina, Alberto, Ignazio Angeloni, and Federico Etro. 2005. "International Unions." American Economic Review, 95:3, 602-615.

Alonso, Ricardo, Wouter Dessein and Niko Matouschek. 2008. "When Does Coordination Require Centralization?" American Economic Review, 98:1, 145-179.

Besley, Timothy and Stephen Coate. 2003. "Centralized versus Decentralized Provision of Local Public Goods: A Political Economy Approach." Journal of Public Economics, 87:12, 2611-2637.

Carbonara, Emanuela and Francesco Parisi. 2007. "The Paradox of Legal Harmonization." Public Choice, 132:2, 367-400.

Carbonara, Emanuela and Francesco Parisi. 2009. "Choice of Law and Legal Evolution: Rethinking the Market for Legal Rules." Public Choice, 139:3, 461-492.

Casella, Alessandra and Jonathan S. Feinstein. 2002. "Public Goods in Trade: On the Formation of Markets and Jurisdictions." International Economic Review, 43:2, 437-362.

Crettez, Bertrand, Bruno Deffains, and Regis Deloche. 2009. "On the Optimal Complexity of Law and Legal Rules Harmonization." European Journal of Law and Economics, 27:2, 129-142.

Crettez, Bertrand and Regis Deloche. 2006. "On the Unification of Legal Rules in the European Union." European Journal of Law and Economics, 21:3, 203-214.

Esty, Daniel C. and Damien Geradin. 2000. "Regulatory Co-Opetition." Journal of International Economic Law, 3:2, 235-255.

Esty, Daniel C. and Damien Geradin. 2001. Regulatory Competition and Economic Integration: Comparative Perspectives. Oxford University Press.

Ganuza, Juan Jose and Fernando Gomez. 2008. "Realistic Standards: Optimal Negligence with Limited Liability." Journal of Legal Studies, 37:2, 577-594.

Garoupa, Nuno and Anthony Ogus. 2006. "A Strategic Interpretation of Legal Transplants." Journal of Legal Studies, 35:2, 339-363.

Garro, Alejandro. 1992. "Unification and Harmonization of Private Law in Latin America." American Journal of Comparative Law, 40:3, 587-616.

Gomez, Fernando. 2008. "The Harmonization of Contract Law through European Rules: A Law and Economics Perspective." InDret Working Paper.

Harstad, Bård. 2007. "Harmonization and Side Payments in Political Cooperation." American Economic Review, 97:3, 871-889.

Hay, Jonathan R. and Andrei Shleifer. 1998. "Private Enforcement of Public Laws: A Theory of Legal Reform." American Economic Review, Papers and Proceedings, 88:2, 398-403.

Herings, Jean-Jacques P. and Arnald J. Kanning. 2008. "Harmonization of Private Law on a Global Level." International Review of Law and Economics, 28:4, 256-262. 
Hoel, Michael. 1992. "International Environment Conventions: The Case of Uniform Reductions of Emissions." Environmental and Resource Economics, 2:2, 141-159.

Knill, Christoph and Andrea Lenschow. 2005. "Compliance, Competition and Communication: Different Approaches of European Governance and their Impact on National Institutions." Journal of Common Market Studies, 43:3, 583-606.

Lockwood, Ben. 2002. "Distributive Politics and the Costs of Centralization." Review of Economic Studies, 69:2, 313-337.

Loeper, Antoine. 2009. "Coordination in Heterogeneous Federal Systems." Unpublished manuscript, dated August 2009.

Malang, Zainudin S. 2007. "Economic Integration in the Asian Region: Harmonization of Law." Mindanao Law Journal, 1:1, 34-53.

Mancuso, Salvatore. 2006. "The Harmonization of Commercial Law in Africa: The Project Related to Telecommunications in the OHADA Harmonization Process." Journal of International Trade Law and Policy, 5:2, 55-66.

Marciano, Alain and Jean-Michel Josselin (eds.). 2002. The Economics of Harmonizing European Law. Northampton: Edward Elgar.

Mas-Colell, Andreu, Michael D. Whinston and Jerry R. Green. 1995. Microeconomic Theory. Oxford University Press.

Monheim Helstroffer, Jenny and Marie Obidzinski. 2010. "Optimal Discretion in Asylum Lawmaking." International Review of Law and Economics, 30:1, 86-97.

Mukand, Sharun W. and Dani Rodrik. 2005. "In Search of the Holy Grail: Policy Convergence, Experimentation, and Economic Performance." American Economic Review, 95:1, 374-383.

Oates, Wallace. 1972. Fiscal Federalism. New York: Harcourt Brace Jovanovich.

Ogus, Anthony. 1999. "Competition between National Legal Systems: A Contribution of Economic Analysis to Comparative Law." International and Comparative Law Quarterly, 48, 405-418.

O'Hara, Erin A. and Larry E. Ribstein. 2000. "Conflict of Laws and Choice of Laws." In Bouckaert, Boudewijn and Gerrit De Geest (eds.), Encyclopedia of Law and Economics, Volume $V$. The Economics of Crime and Litigation, Cheltenham, Edward Elgar, 631-660.

O'Hara, Erin A. and Larry E. Ribstein. 2009. The Law Market. Oxford University Press.

Parisi, Francesco. 2007. "Harmonization of European Private Law: An Economic Analysis." University of Minnesota Law School Legal Studies Research Paper No. 07-41.

Rantakari, Heikko. 2008. "Governing Adaptation." Review of Economic Studies, 75:4, 12571285.

Reich, Arie. 2004. "The WTO as a Law-Harmonizing Institution." University of Pennsylvania Journal of International Economic Law, 25:1 321-382.

Ribstein, Larry E. and Bruce H. Kobayashi. 1996. "An Economic Analysis of Uniform State Laws." Journal of Legal Studies, 25:1, 131-199. 
Rodrik, Dani. 2000. "How Far Will International Economic Integration Go?" Journal of Economic Perspectives, 14:1, 177-186.

Rodrik, Dani. 2001. "The Global Governance of Trade. As if Development Really Mattered." Background paper for UNDP project on Trade and Sustainable Human Development.

Sgard, Jérôme. 2004. "Are There Such Things as International Property Rights?" World Economy, 27:3, 387-401.

Smits, Jan. 2002. "How to Predict the Differences in Uniformity between Different Areas of a Future European Private Law? An Evolutionary Approach." In: Marciano, Alain and JeanMichel Josselin (eds.), The Economics of Harmonizing European Law, Northampton: Edward Elgar, 50-70.

Sydsæter, Knut, Arne Strøm and Peter Berck. 2005. Economists' Mathematical Manual, Fourth Edition, Berlin: Springer-Verlag.

Sykes, Alan. 2000. "Regulatory Competition or Regulatory Harmonization? A Silly Question?" Journal of International Economic Law, 3:2, 257-264.

Ulph, Alistair. 2000. "Harmonization and Optimal Environmental Policy in a Federal System with Asymmetric Information." Journal of Environmental Economics and Management, 39:2, 224-241.

Van den Bergh, Roger. 2000. "Towards an Institutional Legal Framework for Regulatory Competition in Europe." Kyklos, 53:4, 435-466.

IUC Global Legal Standards Research Group. 2009. "IUC Independent Policy Report: At the End of the End of History - Global Legal Standards: Part of the Solution or Part of the Problem?" Global Jurist, 9:3, Article 2. 


\section{Appendix A}

Let $b_{i} \equiv \mathrm{E}_{\theta_{i}}\left[L_{i}\left(\theta_{i}\right)\right]$ so that the system (5) can be written as $b_{i}-\sum_{j \neq i} \gamma_{i j} b_{j}=0, i \in\{1, \ldots, n\}$, or in matrix form as:

$$
\left[\begin{array}{cccc}
1 & -\gamma_{12} & \ldots & -\gamma_{1 n} \\
-\gamma_{21} & 1 & \ldots & -\gamma_{2 n} \\
\vdots & \vdots & \ddots & \vdots \\
-\gamma_{n 1} & -\gamma_{n 2} & \ldots & 1
\end{array}\right]\left[\begin{array}{c}
b_{1} \\
b_{2} \\
\vdots \\
b_{n}
\end{array}\right]=\left[\begin{array}{c}
0 \\
0 \\
\vdots \\
0
\end{array}\right]
$$

The matrix pre-multiplying the column vector of $b_{i}$ 's is a dominant diagonal matrix. Since every dominant diagonal matrix is nonsingular (Sydsæter et al. 2005: 153), the system (5) has a unique solution of $b_{i} \equiv \mathrm{E}_{\theta_{i}}\left[L_{i}\left(\theta_{i}\right)\right]=0$ for all $i \in\{1, \ldots, n\}$.

\section{Appendix B}

To show that harmonization through delegation $(H d)$ can be the best institutional regime from the aggregate welfare viewpoint even in the presence of a symmetric $\Gamma$, consider the following example for $n=3$ :

$$
\boldsymbol{\Gamma}=\left[\begin{array}{lll}
0.98 & 0.01 & 0.01 \\
0.01 & 0.01 & 0.98 \\
0.01 & 0.98 & 0.01
\end{array}\right]
$$

The above symmetric $\Gamma$ implies that none of the three jurisdictions are focal, and that jurisdiction 1 is autonomous. Thus, $H d$ (when lawmaking authority is delegated to jurisdiction 1 ) dominates $H C$ because $0.98-0.01-0.01>0$ (see Lemma 2). To see that $H d$ also dominates $D$, apply expression (13) (or Lemma 3) to obtain:

$$
\begin{aligned}
\mathrm{E} W^{H d}-\mathrm{E} W^{D} & =(0.98-0.01-0.01)-\left(0.98^{2} \times(1-0.01-0.01)+2 \times 0.01^{2} \times(1-0.98-0.01)\right) \\
& =0.018806>0 .
\end{aligned}
$$




\section{Appendix C}

To show that, in the presence of a dominant jurisdiction, the regime of decentralized standardsetting can be the best institutional regime from the aggregate welfare viewpoint, consider the following example for $n=3$ :

$$
\boldsymbol{\Gamma}=\left[\begin{array}{lll}
0.52 & 0.24 & 0.24 \\
0.52 & 0.24 & 0.24 \\
0.52 & 0.24 & 0.24
\end{array}\right]
$$

The above $\Gamma$ implies that jurisdiction 1 is both focal and autonomous, and thus, by Definition 3 , dominant. Then, $D$ welfare dominates $H C$ because $0.52^{2} \times(1-0.52-0.52)+$ $2 \times 0.24^{2} \times(1-0.24-0.24)=0.07072>0($ see Lemma 1$)$. Moreover, $D$ also welfare dominates the regime where the authority to set the common legal standard is allocated to the dominant jurisdiction $1(H d)$ because (apply expression (13))

$$
\begin{aligned}
\mathrm{E} W^{H d}-\mathrm{E} W^{D} & =(0.52-0.24-0.24)-\left(0.52^{2} \times(1-0.52-0.52)+2 \times 0.24^{2} \times(1-0.24-0.24)\right) \\
& =-0.03072<0 .
\end{aligned}
$$




\section{CESifo Working Paper Series}

for full list see www.cesifo-group.org/wp

(address: Poschingerstr. 5, 81679 Munich, Germany, office@cesifo.de)

3021 Karl Ove Aarbu, Demand Patterns for Treatment Insurance in Norway, April 2010

3022 Toke S. Aidt and Jayasri Dutta, Fiscal Federalism and Electoral Accountability, April 2010

3023 Bahram Pesaran and M. Hashem Pesaran, Conditional Volatility and Correlations of Weekly Returns and the VaR Analysis of 2008 Stock Market Crash, April 2010

3024 Stefan Buehler and Dennis L. Gärtner, Making Sense of Non-Binding Retail-Price Recommendations, April 2010

3025 Leonid V. Azarnert, Immigration, Fertility, and Human Capital: A Model of Economic Decline of the West, April 2010

3026 Christian Bayer and Klaus Wälde, Matching and Saving in Continuous Time: Theory and 3026-A Matching and Saving in Continuous Time: Proofs, April 2010

3027 Coen N. Teulings and Nick Zubanov, Is Economic Recovery a Myth? Robust Estimation of Impulse Responses, April 2010

3028 Clara Graziano and Annalisa Luporini, Optimal Delegation when the Large Shareholder has Multiple Tasks, April 2010

3029 Erik Snowberg and Justin Wolfers, Explaining the Favorite-Longshot Bias: Is it RiskLove or Misperceptions?, April 2010

3030 Doina Radulescu, The Effects of a Bonus Tax on Manager Compensation and Welfare, April 2010

3031 Helmut Lütkepohl, Forecasting Nonlinear Aggregates and Aggregates with Timevarying Weights, April 2010

3032 Silvia Rocha-Akis and Ronnie Schöb, Welfare Policy in the Presence of Unionised Labour and Internationally Mobile Firms, April 2010

3033 Steven Brakman, Robert Inklaar and Charles van Marrewijk, Structural Change in OECD Comparative Advantage, April 2010

3034 Dirk Schindler and Guttorm Schjelderup, Multinationals, Minority Ownership and TaxEfficient Financing Structures, April 2010

3035 Christian Lessmann and Gunther Markwardt, Decentralization and Foreign Aid Effectiveness: Do Aid Modality and Federal Design Matter in Poverty Alleviation?, April 2010 
3036 Eva Deuchert and Conny Wunsch, Evaluating Nationwide Health Interventions when Standard Before-After Doesn't Work: Malawi's ITN Distribution Program, April 2010

3037 Eric A. Hanushek and Ludger Woessmann, The Economics of International Differences in Educational Achievement, April 2010

3038 Frederick van der Ploeg, Aggressive Oil Extraction and Precautionary Saving: Coping with Volatility, April 2010

3039 Ainura Uzagalieva, Evžen Kočenda and Antonio Menezes, Technological Imitation and Innovation in New European Union Markets, April 2010

3040 Nicolas Sauter, Jan Walliser and Joachim Winter, Tax Incentives, Bequest Motives, and the Demand for Life Insurance: Evidence from two Natural Experiments in Germany, April 2010

3041 Matthias Wrede, Multinational Capital Structure and Tax Competition, April 2010

3042 Burkhard Heer and Alfred Maussner, A Note on the Computation of the Equity Premium and the Market Value of Firm Equity, April 2010

3043 Kristiina Huttunen, Jukka Pirttilä and Roope Uusitalo, The Employment Effects of Low-Wage Subsidies, May 2010

3044 Matthias Kalkuhl and Ottmar Edenhofer, Prices vs. Quantities and the Intertemporal Dynamics of the Climate Rent, May 2010

3045 Bruno S. Frey and Lasse Steiner, Pay as you Go: A New Proposal for Museum Pricing, May 2010

3046 Henning Bohn and Charles Stuart, Population under a Cap on Greenhouse Gas Emissions, May 2010

3047 Balázs Égert and Rafal Kierzenkowski, Exports and Property Prices in France: Are they Connected?, May 2010

3048 Thomas Eichner and Thorsten Upmann, Tax-Competition with Involuntary Unemployment, May 2010

3049 Taiji Furusawa, Kazumi Hori and Ian Wooton, A Race beyond the Bottom: The Nature of Bidding for a Firm, May 2010

3050 Xavier Vives, Competition and Stability in Banking, May 2010

3051 Thomas Aronsson and Erkki Koskela, Redistributive Income Taxation under Outsourcing and Foreign Direct Investment, May 2010

3052 Michael Melvin and Duncan Shand, Active Currency Investing and Performance Benchmarks, May 2010 
3053 Sören Blomquist and Laurent Simula, Marginal Deadweight Loss when the Income Tax is Nonlinear, May 2010

3054 Lukas Menkhoff, Carol L. Osler and Maik Schmeling, Limit-Order Submission Strategies under Asymmetric Information, May 2010

3055 M. Hashem Pesaran and Alexander Chudik, Econometric Analysis of High Dimensional VARs Featuring a Dominant Unit, May 2010

3056 Rabah Arezki and Frederick van der Ploeg, Do Natural Resources Depress Income Per Capita?, May 2010

3057 Joseph Plasmans and Ruslan Lukach, The Patterns of Inter-firm and Inter-industry Knowledge Flows in the Netherlands, May 2010

3058 Jenny E. Ligthart and Sebastian E. V. Werner, Has the Euro Affected the Choice of Invoicing Currency?, May 2010

3059 Håkan Selin, Marginal Tax Rates and Tax-Favoured Pension Savings of the SelfEmployed - Evidence from Sweden, May 2010

3060 Richard Cornes, Roger Hartley and Yuji Tamura, A New Approach to Solving Production-Appropriation Games with Many Heterogeneous Players, May 2010

3061 Ronald MacDonald and Flávio Vieira, A Panel Data Investigation of Real Exchange Rate Misalignment and Growth, May 2010

3062 Thomas Eichner and Rüdiger Pethig, Efficient Management of Insecure Fossil Fuel Imports through Taxing(!) Domestic Green Energy?, May 2010

3063 Vít Bubák, Evžen Kočenda and Filip Žikeš, Volatility Transmission in Emerging European Foreign Exchange Markets, May 2010

3064 Leonid V. Azarnert, Après nous le Déluge: Fertility and the Intensity of Struggle against Immigration, May 2010

3065 William E. Becker, William H. Greene and John J. Siegfried, Do Undergraduate Majors or Ph.D. Students Affect Faculty Size?, May 2010

3066 Johannes Becker, Strategic Trade Policy through the Tax System, May 2010

3067 Omer Biran and Françoise Forges, Core-stable Rings in Auctions with Independent Private Values, May 2010

3068 Torben M. Andersen, Why do Scandinavians Work?, May 2010

3069 Andrey Launov and Klaus Wälde, Estimating Incentive and Welfare Effects of NonStationary Unemployment Benefits, May 2010 
3070 Simon Gächter, Benedikt Herrmann and Christian Thöni, Culture and Cooperation, June 2010

3071 Mehmet Bac and Eren Inci, The Old-Boy Network and the Quality of Entrepreneurs, June 2010

3072 Krisztina Molnár and Sergio Santoro, Optimal Monetary Policy when Agents are Learning, June 2010

3073 Marcel Boyer and Donatella Porrini, Optimal Liability Sharing and Court Errors: An Exploratory Analysis, June 2010

3074 Guglielmo Maria Caporale, Roman Matousek and Chris Stewart, EU Banks Rating Assignments: Is there Heterogeneity between New and Old Member Countries? June 2010

3075 Assaf Razin and Efraim Sadka, Fiscal and Migration Competition, June 2010

3076 Shafik Hebous, Martin Ruf and Alfons Weichenrieder, The Effects of Taxation on the Location Decision of Multinational Firms: M\&A vs. Greenfield Investments, June 2010

3077 Alessandro Cigno, How to Deal with Covert Child Labour, and Give Children an Effective Education, in a Poor Developing Country: An Optimal Taxation Problem with Moral Hazard, June 2010

3078 Bruno S. Frey and Lasse Steiner, World Heritage List: Does it Make Sense?, June 2010

3079 Henning Bohn, The Economic Consequences of Rising U.S. Government Debt: Privileges at Risk, June 2010

3080 Rebeca Jiménez-Rodriguez, Amalia Morales-Zumaquero and Balázs Égert, The VARying Effect of Foreign Shocks in Central and Eastern Europe, June 2010

3081 Stephane Dees, M. Hashem Pesaran, L. Vanessa Smith and Ron P. Smith, Supply, Demand and Monetary Policy Shocks in a Multi-Country New Keynesian Model, June 2010

3082 Sara Amoroso, Peter Kort, Bertrand Melenberg, Joseph Plasmans and Mark Vancauteren, Firm Level Productivity under Imperfect Competition in Output and Labor Markets, June 2010

3083 Thomas Eichner and Rüdiger Pethig, International Carbon Emissions Trading and Strategic Incentives to Subsidize Green Energy, June 2010

3084 Henri Fraisse, Labour Disputes and the Game of Legal Representation, June 2010

3085 Andrzej Baniak and Peter Grajzl, Interjurisdictional Linkages and the Scope for Interventionist Legal Harmonization, June 2010 